\title{
EVALUASI KINERJA DAERAH IRIGASI CIKEUSIK BERDASARKAN PETUNJUK PELAKSANAAN GABUNGAN PENILAIAN KINERJA IRIGASI KEMENTERIAN PEKERJAAN UMUM DAN PERUMAHAN RAKYAT (PUPR) TAHUN 2017
}

\section{Performance Evaluation Cikeusik Irrigation Area Based on Combined Instructions for Irrigation Performance Assessment of the Ministry of Public and Household Housing (PUPR) in 2017}

\author{
Kiki Rishki Ananda ${ }^{1) *}$, Latief Mahir Rachman ${ }^{2)}$ dan Suria Darma Tarigan ${ }^{2)}$ \\ 1)Program Studi Ilmu Pengelolaan DAS, Sekolah Pascasarjana, IPB University, \\ Jl. Meranti Kampus IPB Dramaga, Bogor 16680 \\ 2)Departemen Ilmu Tanah dan Sumberdaya Lahan, Fakultas Pertanian, IPB University, \\ Jl. Meranti Kampus IPB Dramaga, Bogor 16680
}

\begin{abstract}
The Cikeusik irrigation area was built in 1883 and started operation in 1884, but its operation now is not optimum. Cikeusik irrigation area is located at Cikeusik District, Pandeglang Regency, Banten Province. Agriculture sector in that area has a great potensial. Cikeusik District has a 650 hectar of agricultural land. Cikeusik irrigation area is a technical irrigation network that has 9 intake gates. Right now, Cikeusik irrigation area water supply to tertiary plots is getting shortened. This study aim to evaluate the performance of D.I. Cikeusik. The method used in this research is guidance of joint implementation of performance assessment of main and tertiary irrigation system of ministry of PUPR 2017. The result of research indicated that Irrigation System Performance Value (NKSI) is still lacking.
\end{abstract}

Keywords: Irrigation system performance value, irrigation network, tertiary plots

\section{ABSTRAK}

Daerah irigasi (D.I.) Cikeusik dibangun pada tahun 1883 dan mulai beroperasi pada tahun 1884, namun saat ini sudah tidak beroperasi secara optimum. D.I. Cikeusik terletak di Kecamatan Cikeusik, Kabupaten Pandeglang, Provinsi Banten. Sektor pertanian yang terdapat di daerah tersebut memiliki potensi yang sangat baik. Kecamatan Cikeusik mempunyai lahan pertanian seluas 650 ha. Jaringan irigasi di D.I. Cikeusik mencakup jaringan irigasi teknis yang memiliki sembilan buah pintu sadap. Saat ini irigasi Cikeusik mengalami perubahan dalam pemasokan air ke petak tersier, air yang dipasok tidak tercukupi. Penelitian ini bertujuan untuk mengevaluasi kinerja D.I. Cikeusik. Metode yang digunakan dalam penelitian ini adalah menggunakan petunjuk pelaksanaan gabungan penilaian kinerja sistem irigasi utama dan tersier kementerian PUPR 2017. Hasil penelitian menunjukkan bahwa Nilai Kinerja Sistem Irigasi (NKSI) sebesar 64.86\% termasuk kategori kinerja irigasi masih kurang.

Kata kunci: Nilai kinerja sistem irigasi, jaringan irigasi, petak tersier

\section{PENDAHULUAN}

Pemenuhan air irigasi masih menjadi isu utama yang layak dikaji di setiap Daerah Irigasi (D.I). Ketidakseimbangan penyediaan dengan kebutuhan air menjadi permasalahan utama di setiap daerah, mengingat program kerja dari pemerintah saat ini dalam upaya peningkatan hasil pertanian yang didukung oleh ketersediaan pasokan air irigasi belum mencapai optimum.

Pengelolaan terhadap irigasi yang baik diperlukan agar dapat menjamin ketersediaan air selama berlangsungnya musim tanam sesuai dengan kebutuhan normal masing-masing tanaman, setidaknya kebutuhan air minimum terpenuhi. Menurut Wickham dan Valera (1976) manajemen air yang baik akan memungkinkan para petani untuk melakukan penanaman padi dengan air yang cukup, dimulai dari proses penanaman sampai datangnya masa panen.

Jumlah kebutuhan air untuk irigasi pada umumnya di pengaruhi beberapa faktor yaitu jenis tanah, sifat tanah, macam dan jenis tanaman, keadaan iklim, keadaan topografi dan luar komplek areal kebutuhan air irigasi dapat di bedakan atas kebutuhan untuk pertumbuhan tanaman, kebutuhan air untuk petak sawah, dan kehilangan air selama penyaluran (Arsyad, 2010).

Menurut Hardjowigeno (2003) ketersediaan air dalam tanah tergantung dari banyaknya curah hujan, kemampuan tanah menahan air, besarnya evapotranspirasi, dan tingginya muka air tanah. Air dapat meresap atau ditahan oleh tanah karena adanya gaya-gaya adhesi, kohesi, dan gravitasi. Karena adanya gaya-gaya tersebut maka air di dalam tanah dibedakan dua yaitu: (1) Air higroskopik adalah air yang diserap tanah sangat kuat sehingga tidak dapat digunakan tanaman (adhesi antara tanah dan air); (2) Air kapiler air dalam tanah dimana daya kohesi tarik menarik antara butir-butir air dan daya adhesi antara air dan tanah lebih kuat dari gravitasi (Baskoro dan Tarigan, 2007). Air ini dapat bergerak ke samping atau ke atas karena gaya-gaya kapiler. Sebagian besar dari air kapiler merupakan air yang tersedia bagi tanaman. 
Saluran irigasi Cikeusik mempunyai permasalahan dalam hal pengelolaan air sehingga irigasi tersebut tidak berfungsi sebagaimana mestinya. Keberadaan irigasi seharusnya berfungsi untuk meningkatkan potensi pertanian di D.I Cikeusik. Namun saat ini di D.I Cikeusik terdapat ketidakstabilan dalam pengelolaan air untuk kegiatan pertanian bahkan dapat merugikan petani baik pada musim kemarau dan musim hujan akibat dari pengelolaan air yang tidak tepat. Hal ini terjadi dikarenakan terdapat perubahan fungsi pembangunan irigasi teknis di D.I Cikeusik. Selain itu permasalahn lain dapat disebabkan perubahan penggunaan lahan dimana tutupan hutan yang berkurang di hulu sebuah DAS dapat menyebabkan terjadinya fluktuasi sumberdaya air dan kekritisan sebuah DAS (Banuwa, 2008; Junaidi dan Tarigan, 2011; Tarigan et al., 2016; Tarigan et al., 2018)

\section{BAHAN DAN METODE}

Penelitian dilaksanakan selama 9 bulan dari bulan April 2017 hingga Januari 2018. Lokasi Penelitian terletak di DAS Cibaliung pada sub DAS Cikeusik yang secara Astronomis D.I Cikeusik terletak pada $6^{\circ} 43^{\prime} 06^{\prime \prime} \mathrm{LS}$ dan $105^{\circ} 52^{\prime} 19^{\prime}$ ' BT dengan elevasi $21 \mathrm{~m}$ di atas permukaan laut pada bendung Cikeusik dan $6^{\circ} 44^{\prime} 19^{\prime \prime}$ LS dan $105^{\circ}$ 53'06" BT dengan elevasi $19 \mathrm{~m}$ di atas permukaan laut di hilir jaringan irigasi Cikeusik dengan luas yang diairi 650 ha (Gambar 1). Analisis fisik dilakukan pada laboratorium fisika tanah Departemen Ilmu Tanah dan sumber Daya Lahan IPB.

\section{Alat dan Bahan}

Alat yang digunakan dalam penelitian adalah seperangkat komputer, Global Positioning System (GPS), ring sampler, double ring infiltrometer dan alat-alat lainnya yang diperlukan untuk pengambilan sample tanah dan analisis di laboratorium. Adapun bahan yang digunakan dalam penelitian terdiri dari: (i) data curah hujan, suhu, kelembaban udara, kecepatan angin dan radiasi matahari) tahun 2007-2016, (ii) skema jaringan Irigasi, (iii) pola tanaman aktual, (iv) peta jaringan irigasi.

\section{Metode Penelitian}

Penelitian yang dilakukan ini diawali dengan tahap pengumpulan data sekunder, survei lapang (pengumpulan data primer), analisis data dan penulisan hasil penelitian.

\section{Pengamatan Lapangan}

Pengamatan lapangan dilakukan dengan mengadakan observasi langsung pada daerah irigasi Cikeusik. Pengamatan dimulai dengan mengumpulkan data primer dan data sekunder. Data primer dikumpulkan langsung dilapangan. Data primer dalam penelitian terdiri dari sistem pasokan air, kondisi bangunan irigasi, kualitas air, ketinggian sedimentasi dan sumber ketersediaan air. Data primer di ambil dengan pengambilan sampel tanah, sampel air muatan sedimen, wawancara petugas dan petani dengan mengisi kuisioner, dan pengukuran tinggi air di jaringan irigasi tersier (Gambar 2).

\section{Evaluasi Kinerja Irigasi menggunakan Pedoman Kementrian Pekerjaan Umum dan Perumahan Rakyat (PUPR)}

Evaluasi Kinerja Irigasi pedoman Kementrian PUPR (2017) pusat terbagi atas 2 yaitu indikator penilaian sistem irigasi utama dan pengelolaan sistem irigasi tersier. Indikator penilaian irigasi utama dapat dilihat pada Tabel 1 .

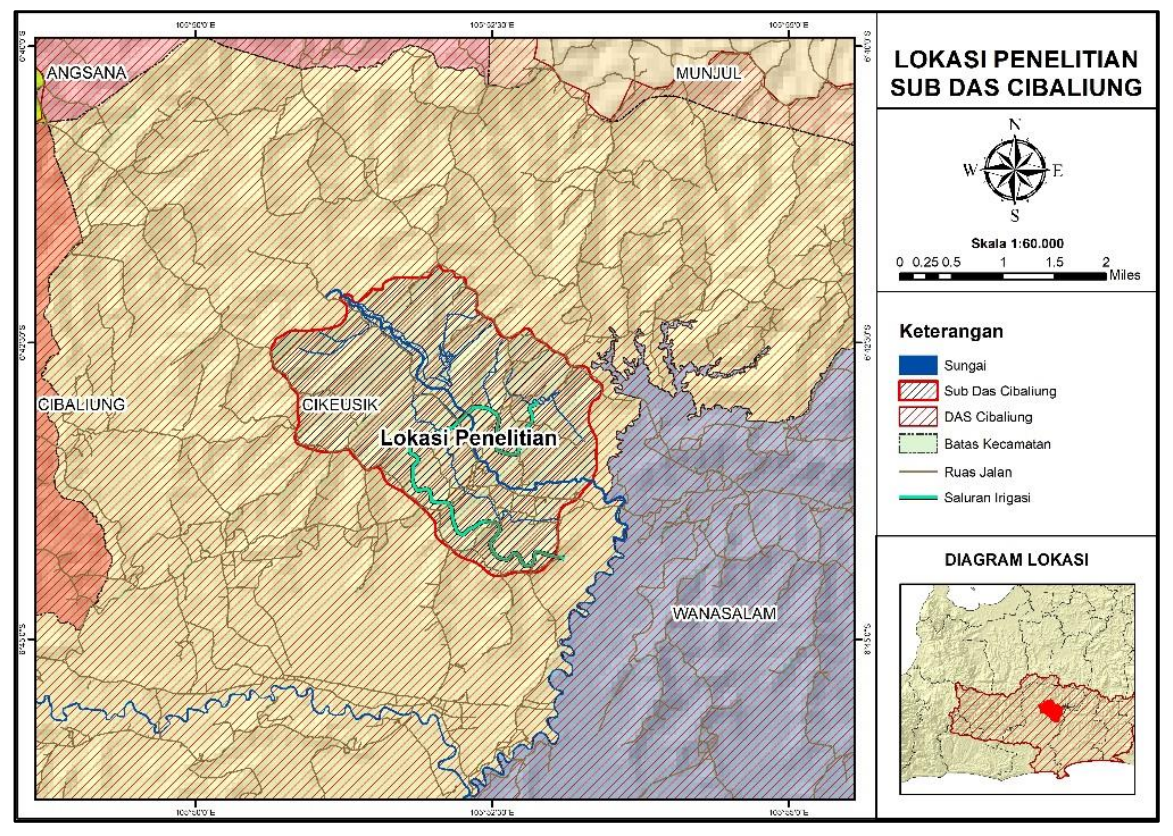

Gambar 1. Lokasi penelitian (D.I. Cikeusik) 


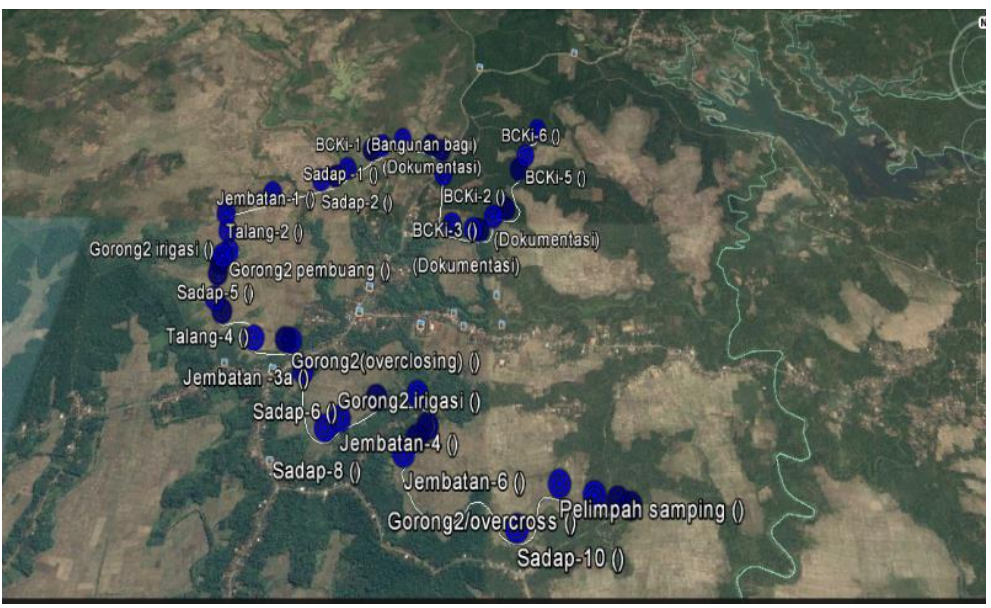

Gambar 2. Peta lokasi pengambilan data

Tabel 1. Bobot dan indikator penilaian sistem irigasi utama

\begin{tabular}{|c|c|c|c|}
\hline No & Komponen & Indikator & Bobot \\
\hline 1 & Prasarana Fisik & $\begin{array}{ll}\text { - } & \text { Bangunan utama } \\
\text { - } & \text { Saluran pembawa } \\
\text { - } & \text { Bangunan pada saluran pembawa } \\
\text { - } & \text { Saluran pembuang dan bangunannya } \\
\text { - } & \text { Jalan masuk/inpeksi } \\
\text { - } & \text { Kantor, perumahan, dan gudang } \\
\end{array}$ & $45 \%$ \\
\hline 2 & Produktivitas tanam & $\begin{array}{ll}\text { - } & \text { Pemenuhan kebutuhan air (faktor K) } \\
\text { - } & \text { Realisasi luas tanam } \\
\text { - } & \text { Produktivitas padi } \\
\end{array}$ & $15 \%$ \\
\hline 3 & Sarana penunjang & $\begin{array}{ll}\text { - } & \text { Peralatan O Dan P } \\
\text { - } & \text { Transportasi } \\
\text { - } & \text { Alat-alat kantor ranting/pengamat/UPTD } \\
\text { - } & \text { Alat komunikasi } \\
\end{array}$ & $10 \%$ \\
\hline 4 & Organisasi personalia & $\begin{array}{l}\text { - Organisasi O dan P telah disusun dengan batasan-batasan tanggungjawab dan tugas yang jelas } \\
\text { - } \quad \text { Personalia }\end{array}$ & $15 \%$ \\
\hline 5 & Dokumentasi & $\begin{array}{ll}\text { - } & \text { Buku data Daerah Irigasi } \\
\text { - } & \text { Peta dan gambar-gambar } \\
\end{array}$ & $5 \%$ \\
\hline 6 & $\begin{array}{l}\text { Perkumpulan petani Pemakai air } \\
\text { (GP3A/IP3A) }\end{array}$ & $\begin{array}{ll}\text { - } & \text { GP3A/IP3A sudah berbadan hukum } \\
\text { - } & \text { Kondisi kelembagaan GP3A/IP3A } \\
\text { - } & \text { Rapat Ulu-ulu/P3A Desa/GP3A/IP3A dengan Ranting/Pengamat/UPTD } \\
\text { - } & \text { GP3A aktif mengikuti survei/penelusuran jaringan } \\
\text { - } & \text { Partisipasi anggota GP3A/IP3A dalam perbaikan jaringan dan penanganan bencana alam } \\
\text { - } & \text { Iuran GP3A/IP3A untuk partisipasi perbaikan jaringan utama } \\
\text { - } & \text { Partisipasi GP3A/IP3A dalam perencanaan tata tanam dan pengalokasikan air } \\
\end{array}$ & $10 \%$ \\
\hline
\end{tabular}

Sumber: Petunjuk pelaksanaan gabungan penilaian kinerja sistem irigasi utama dan tersier Kementrian PUPR (2017).

Tabel 2. Indikator penilaian sistem irigasi tersier

\begin{tabular}{|c|c|c|c|}
\hline No & Komponen & Indikator & Bobot \\
\hline 1 & Prasarana Fisik & $\begin{array}{ll}- & \text { Saluran pembawa } \\
\text { - } & \text { bangunan pada saluran pembawa } \\
\text { - } & \text { Saluran pembuang dan bangunannya } \\
\end{array}$ & $25 \%$ \\
\hline 2 & Produktivitas tanaman & $\begin{array}{ll}- & \text { Pemenuhan kebutuhan air (faktor K) } \\
\text { - } & \text { Realisasi luas tanam } \\
\text { - } & \text { Produktifitas padi }\end{array}$ & $15 \%$ \\
\hline 3 & Kondisi $\mathrm{O}$ dan $\mathrm{P}$ & $\begin{array}{ll}\text { - } & \text { Tingkat adanya bobolan } \\
\text { - } & \text { Giliran pembagian air waktu debit kecil } \\
\text { - } & \text { Pembersihan saluran tersier } \\
\text { - } & \text { Perlengkapan pendukung OP }\end{array}$ & $20 \%$ \\
\hline 4 & $\begin{array}{l}\text { Petugas O dan } \mathrm{P} / \\
\text { Organisasi Personalia }\end{array}$ & $\begin{array}{ll}- & \text { Ulu-ulu/petugas teknis P3A tersedia } \\
\text { - } & \text { Ulu-ulu/petugas teknis P3A telah terlatih } \\
\text { - } & \text { Ulu-ulu/petugas teknis P3A sering komunikasi dengan petani dan juru pengairan }\end{array}$ & $15 \%$ \\
\hline 5 & Dokumentasi & $\begin{array}{ll}- & \text { Buku data petak tersier } \\
\text { - } & \text { Peta dan gambar-gambar }\end{array}$ & $5 \%$ \\
\hline 6 & $\mathrm{P} 3 \mathrm{~A}$ & $\begin{array}{ll}\text { - } & \text { Status badan hukum P3A } \\
\text { - } & \text { Kondisi kelembagaan } \\
\text { - } & \text { Aktivitas rapat-rapat P3A } \\
\text { - } & \text { Aktivitas survey/penelusuran jaringan } \\
\text { - } & \text { Partisipasi anggota P3A dalam perbaikan jaringan dan penanganan bencana alam } \\
\text { - } & \text { Iuran OP untuk tersier } \\
\text { - } & \text { Kemampuan fungsional dan koordinasi dalam perencanaan tata tanam dan pengalokasian air } \\
\text { - } & \text { keterlibatan P3A dalam monitoring dan evaluasi }\end{array}$ & $20 \%$ \\
\hline
\end{tabular}

Sumber: Petunjuk pelaksanaan gabungan penilaian kinerja sistem irigasi utama dan tersier Kementrian PUPR (2017). 


\section{Indikator Penilaian}

Dalam penentuan indikator penilaian dibagi dalam beberapa kelompok kondisi dan kinerja berikut:

a. Prasarana fisik ada 4 indikator terdiri:

- Kondisi baik sekali (>90-100\%) atau tingkat kerusakan $=>0-10 \%$

- Kondisi rusak ringan (>80-90\%) atau tingkat kerusakan $=>10-20 \%$

- Kondisi rusak sedang (>60-80\%) atau tingkat kerusakan $=20-40 \%$

- Kondisi rusak berat $(<60 \%)$ atau tingkat kerusakan $=40 \%$

b. Untuk non fisik (produktivitas tanaman, kondisi OP, petugas OP/organisasi personalia, dokumentasi dan P3A) ada 4 indikator kinerja terdiri:

- Kinerja baik sekali (>80-90\%)

- Kinerja cukup (>60-80\%)

- Kinerja kurang $(>60 \%)$

\section{Kategori Kinerja}

Berdasarkan hasil penilaian kinerja sistem irigasi utama dihasilkan indeks kinerja dengan nilai:

- $80-100 \%$ : Kinerja sangat baik

- $70-<80 \%$ : Kinerja baik

- 55 - $<70 \%$ : kinerja kurang

- $<50 \quad$ : kinerja jelek

Penilaian kinerja sistem irigasi berdasarkan Kementrian Pekerjaan Umum dan Perumahan Rakyat (PUPR) 2017 adalah bobot dan indikator penilaian sistem irigasi dibagi 2 yaitu penilaian sistem irigasi utama dan tersier. Untuk lebih rinci bobot dan indikator yang dinilai dapat dilihat pada Tabel 3.

\section{HASIL DAN PEMBAHASAN}

Curah hujan rata-rata pada D.I. Cikeusik dari tahun 2007-2026 yaitu sebesar 3,935.3 mm dengan curah hujan tertinggi terjadi pada tahun 2010 sebesar $4,960 \mathrm{~mm}$, sementara curah hujan terendah terjadi pada tahun 2011 sebesar 2,811 mm. Rata-rata curah hujan tertinggi terjadi pada bulan Januari sebesar $675 \mathrm{~mm}$, sedangkan rata-rata curah hujan bulanan terendah terjadi pada bulan Agustus sebesar $114 \mathrm{~mm}$. Suhu rata-rata selama 5 tahun terakhir (2012-2016) adalah $33.3^{\circ} \mathrm{C}$, dengan rata-rata suhu tahunan yaitu pada tahun 2014 sebesar $34.1{ }^{\circ} \mathrm{C}$, sedangkan terendah terjadi pada tahun 2016 sebesar $32.3^{\circ} \mathrm{C}$.

Pada Daerah Irigasi Cikeusik saluran pembawa terdiri dari dua yaitu saluran sekunder kiri dan saluran sekunder kanan. Saluran sekunder kiri terdiri dari delapan box sekunder bagi dan sepuluh box sekunder bagi pada saluran sekunder kanan. Permeabilitas untuk saluran sekunder kiri yaitu sebesar 18.98 dan 18.29 sekunder kanan, menunjukkan permeabilitas yang relatif cepat. D.I Cikeusik memiliki kadar air tersedia yang cukup rendah.

\section{Hasil Penilaian Evaluasi D.I. Cikeusik}

Penilaian evaluasi kinerja irigasi dianalisa dengan pedoman evaluasi kinerja irigasi Kementrian Pekerjaan Umum dan Perumahan Rakyat (2017). Penilaian irigasi PUPR (2017) sesuai disajikan pada Tabel 4 dan 5.

\section{Rekomendasi Evaluasi Kinerja Irigasi}

1. Evaluasi irigasi harus mencakup semua aspek fisikteknis, ekonomi, kelembagaan, lingkunngan, sosial dan budaya.

2. Arahan evaluasi irigasi pada PUPR yaitu aspek sarana penunjang organisasi, personalia, dokumentasi, GP3A/IP3A dapat di gabung menjadi satu aspek yaitu aspek kelembagaan.

\section{SIMPULAN}

Berdasarkan hasil evaluasi dengan menggunakan petunjuk pelaksanaan gabungan penilaian kinerja irigasi Kementrian Pekerjaan Umum dan Perumahan Rakyat (PUPR) Tahun 2017, yaitu dengan enam prasarana fisik, produktivitas tanaman, sarana penunjang, organisasi personalia, dokumentasi, dan GP3A/IP3A. Komponenkomponen ini belum terpenuhi dalam menilai kinerja irigasi dikarenakan faktor-faktor lainnya seperti aspek lingkungan, ekonomi, sosial dan budaya yang mempengaruhi kinerja irigasi belum termasuk dalam petunjuk pelaksanan evaluasi irigasi PUPR (2017).

Tabel 3. Rekapitulasi kinerja sistem irigasi

\begin{tabular}{|c|c|c|c|c|c|c|c|}
\hline \multirow[b]{2}{*}{ No } & \multicolumn{3}{|c|}{ Sistem irigasi utama } & \multicolumn{4}{|c|}{ Sistem irigasi tersier } \\
\hline & Komponen & $\begin{array}{c}\text { Indek } \\
\text { kondisi } \\
\text { yang ada }\end{array}$ & $\begin{array}{l}\text { Bobot } \\
(60 \%)\end{array}$ & Komponen & $\begin{array}{c}\text { Indek } \\
\text { kondisi } \\
\text { yang ada }\end{array}$ & $\begin{array}{l}\text { Bobot } \\
(40 \%)\end{array}$ & $\begin{array}{l}\text { Nilai } \\
\text { total }\end{array}$ \\
\hline 1 & Prasarana fisik & 45 & 31 & Prasarana fisik & 25 & 15 & 46 \\
\hline 2 & Produktivitas pertanaman & 15 & 10 & Produktivitas pertanaman & 15 & 10 & 20 \\
\hline 3 & Sarana penunjang & 10 & 5 & Sarana penunjang & 20 & 5 & 10 \\
\hline 4 & Organisasi personalia & 15 & 7 & Organisasi personalia & 15 & 3 & 10 \\
\hline 5 & Dokumentasi & 5 & 2 & Dokumentasi & 5 & 4 & 6 \\
\hline 6 & GP3A/IP3A & 10 & 5 & GP3A/IP3A & 20 & 3 & 8 \\
\hline & Total & 100 & 60 & & 100 & 40 & 100 \\
\hline
\end{tabular}

Keterangan: Alternatif 2 (untuk D.I antara 150 ha - 1000 ha) bobot jaringan utama terhadap total kinerja sebesar $60 \%$ dan $40 \%$ untuk jaringan tersier. 
Tabel 1. Evaluasi kinerja Daerah Irigasi (induk) pedoman Kementrian PUPR

\begin{tabular}{|c|c|c|c|c|}
\hline No & Komponen & Indikator & Nilai & Bobot \\
\hline \multirow[t]{4}{*}{1} & Prasarana Fisik & 1. Saluran pembawa. & 60 & $31 \%$ \\
\hline & & 2. Bangunan pada saluran pembawa. & 50 & \\
\hline & & 3. Saluran pembuang dan bangunannya. & 45 & \\
\hline & & Nilai rata-rata & 51.67 & \\
\hline \multirow[t]{4}{*}{2} & Produktivitas Tanaman & 1. Pemenuhan kebutuhan air (faktor K). & 45 & $10 \%$ \\
\hline & & 2. Realisasi luas tanam. & 70 & \\
\hline & & 3. Produktivitas padi. & 80 & \\
\hline & & Nilai rata-rata & 65 & \\
\hline \multirow[t]{5}{*}{3} & Kondisi $\mathrm{O}$ dan $\mathrm{P}$ & 1. Tingkat adanya bobolan. & 75 & $5 \%$ \\
\hline & & 2. Giliran pembagian air waktu debit kecil. & 75 & \\
\hline & & 3. Pembersihan saluran tersier. & 75 & \\
\hline & & 4. Perlengkapan pendukung OP. & 60 & \\
\hline & & Nilai rata-rata & 71.43 & \\
\hline \multirow[t]{4}{*}{4} & Petugas $\mathrm{O}$ dan $\mathrm{P} /$ & 1. Ulu-ulu/petugas teknis P3A tersedia. & 85 & $7 \%$ \\
\hline & Organisasi Personalia & 2. Ulu-ulu/petugas teknis P3A telah terlatih. & 80 & \\
\hline & & 3. Ulu-ulu/petugas teknis P3A sering komunikasi dengan petani dan juru pengairan. & 85 & \\
\hline & & Nilai rata-rata & 83.33 & \\
\hline \multirow[t]{2}{*}{5} & Dokumentasi & 1. Buku data petak tersier. & 80 & $5 \%$ \\
\hline & & 2. Peta dan gambar-gambar. & 80 & \\
\hline \multirow[t]{9}{*}{6} & $\mathrm{P} 3 \mathrm{~A}$ & 1. Status badan hukum P3A. & 85 & \\
\hline & & 2. Kondisi kelembagaan. & 75 & \\
\hline & & 3. Aktivitas rapat-rapat $\mathrm{P} 3 \mathrm{~A}$. & 75 & \\
\hline & & 4. Aktivitas survey/penelusuran jaringan. & 80 & \\
\hline & & 5. Partisipasi anggota P3A dalam perbaikan jaringan dan penanganan bencana alam. & 75 & \\
\hline & & 6. Iuran OP untuk tersier. & 75 & \\
\hline & & 7. Kemampuan fungsional dan koordinasi dalam perencanaan tata tanam dan pengalokasian air. & 77 & \\
\hline & & 8. Keterlibatan P3A dalam monitoring dan evaluasi. & 75 & \\
\hline & & Nilai rata-rata & 77.7 & \\
\hline
\end{tabular}

Sumber: Penilaian kinerja sistem irigasi tersier pedoman Kementrian Pekerjaan Umum dan Perumahan Rakyat (2017)

Nilai Kinerja Sistem Irigasi (NKSI) ditetapkan sebagai berikut :

$N K S I=\frac{31 \times 51.67+10 \times 65+5 \times 71.43+7 \times 83.33+5 \times 77.7}{100}$

$N K S I=35.81(60 \%)$

Tabel 5. Evaluasi kinerja Daerah Irigasi (tersier) pedoman Kementrian PUPR (2017)

\begin{tabular}{|c|c|c|c|c|}
\hline No & Komponen & Indikator & Nilai & Bobot \\
\hline \multirow[t]{3}{*}{1} & Prasarana Fisik & 1. Saluran pembawa. & 60 & 15 \\
\hline & & 2. Bangunan pada saluran pembawa. & 65 & \\
\hline & & 3. Saluran pembuang dan bangunannya. & 70 & \\
\hline \multirow[t]{4}{*}{2} & Produktivitas tanaman & 1. Pemenuhan kebutuhan air (faktor K). & 75 & 10 \\
\hline & & 2. Realisasi luas tanam. & 80 & \\
\hline & & 3. Produktivitas padi. & 80 & \\
\hline & & Nilai rata-rata & 78.33 & \\
\hline \multirow[t]{5}{*}{3} & Kondisi $\mathrm{O}$ dan $\mathrm{P}$ & 1. Tingkat adanya bobolan. & 75 & 5 \\
\hline & & 2. Giliran pembagian air waktu debit kecil. & 70 & \\
\hline & & 3. Pembersihan saluran tersier. & 75 & \\
\hline & & 4. Perlengkapan pendukung OP. & 70 & \\
\hline & & Nilai rata-rata & 72.50 & \\
\hline \multirow[t]{3}{*}{4} & Petugas O dan $\mathrm{P} /$ & 1. Ulu-ulu/petugas teknis P3A tersedia. & 80 & 3 \\
\hline & Organisasi Personalia & 2. Ulu-ulu/petugas teknis P3A telah terlatih. & 80 & \\
\hline & & 3. Ulu-ulu/petugas teknis P3A sering komunikasi dengan petani dan juru pengairan. & 80 & \\
\hline \multirow{2}{*}{5} & & 2. Peta dan gambar-gambar. & 80 & \\
\hline & & Nilai rata-rata & 80.00 & \\
\hline \multirow[t]{9}{*}{6} & P3A & 1. Status bada hukum P3A. & 75 & 3 \\
\hline & & 2. Kondisi kelembagaan. & 75 & \\
\hline & & 3. Aktivitas rapat-rapat $\mathrm{P} 3 \mathrm{~A}$. & 75 & \\
\hline & & 4. Aktivitas survei/penelusuran jaringan. & 80 & \\
\hline & & 5. Partisipasi anggota P3A dalam perbaikan jaringan dan penanganan bencana alam. & 75 & \\
\hline & & 6. Iuran OP untuk tersier. & 70 & \\
\hline & & 7. Kemampuan fungsional dan koordinasi dalam perencanaan tata tanam dan pengalokasian air. & 75 & \\
\hline & & 8. Keterlibatan P3A dalam monitoring dan evaluasi $(2 \%)$ & 70 & \\
\hline & & Nilai rata-rata & 74.38 & \\
\hline
\end{tabular}

Sumber : Penilaian kinerja sistem irigasi tersier pedoman Kementrian Pekerjaan Umum dan Perumahan Rakyat (2017) 
Nilai Kinerja Sistem Irigasi (NKSI) ditetapkan sebagai berikut :

$$
N K S I=\frac{15 \times 65.00+10 \times 78.33+5 \times 72.50+3 \times 80.00+4 \times 80.00+3 \times 74.38}{100}
$$

NKSIInduk $=35.81(60 \%)$

NKSITersier $=29.04(40 \%)$

NKSITotal $=33.81+29.04=64,86 \%$

Dengan NKSI 64.86 maka 55 - <70\% : kinerja kurang.

\section{DAFTAR PUSTAKA}

Arsyad, S. 2010. Konservasi Tanah dan Air. Institut Pertanian Bogor Press, Bogor.

Banuwa. I.S., N. Sinukaban, S.D. Tarigan dan D. Darusman. 2008. Evaluasi kemampuan lahan DAS Sekampung Hulu. Jurnal Tanah Tropika, 13(2):145-153

Baskoro, D.P.T. dan S.D. Tarigan. 2007. Karakteristik kelembaban tanah pada beberapa jenis tanah. Jurnal Tanah dan Lingkungan, 9(2):77-81

Hardjowigeno, S. 2003. Ilmu Tanah. Akademika Pressindo, Bogor.

Junaidi, E. dan S.D. Tarigan. 2011. Pengaruh hutan dalam pengaturan tata air dan proses sedimentasi Daerah Aliran Sungai (DAS): Studi kasus di DAS Cisadane. Jurnal Penelitian Hutan dan Konservasi Alam, 8(2): 155-176
[Kementerian PUPR]. 2017. Petunjuk Pelaksanaan Gabungan Penilaian Kinerja Sistem Irigasi Utama dan Tersier. Jakarta.

Tarigan, S., K. Wiegand, Sunarti dan B. Slamet. 2018. Minimum forest cover required for sustainablewater flow regulation of a watershed: a case study in Jambi Province, Indonesia. Hydrol. Earth Syst. Sci., 22: 581-594, https://doi.org/10.5194/hess-22-581-2018

Tarigan, S.D., K. Wiegand, C. Dislich, B. Slamet, J. Heinonen dan K. Meyer. 2016. Mitigation options for improving the ecosystem function of water flow regulation in a watershed.

Wickham, T. and A. Valera. 1976. Practice and accountibility for better water management. Paper presented at the West Africa Rice Devi Assoc. Water Management Workshop. 8-10 June 1976, Dakkar, Senegal. 